\title{
EUS-RFA of the pancreas: where are we and future directions
}

\author{
Lakshmi Asritha Gollapudi ${ }^{1}$, Amy Tyberg ${ }^{2}$ \\ ${ }^{1}$ Department of Medicine, Division of Gastroenterology, New York Medical College at Westchester Medical Center, Valhalla, NY, USA; ${ }^{2}$ Rutgers \\ Robert Wood Johnson Medical School, New Brunswick, NJ, USA \\ Contributions: (I) Conception and design: Both authors; (II) Administrative support: None; (III) Provision of study materials or patients: None; (IV) \\ Collection and assembly of data: None; (V) Data analysis and interpretation: None; (VI) Manuscript writing: Both authors; (VII) Final approval of \\ manuscript: Both authors. \\ Correspondence to: Amy Tyberg, MD. Associate Professor of Medicine, Vice Chair of Clinical Affairs, Director of Therapeutic EUS and Associate \\ Director of Endoscopy, Rutgers Robert Wood Johnson Medical School, New Brunswick, NJ, USA. Email: amy.tyberg@gmail.com.
}

\begin{abstract}
Surgical resection remains the gold standard for pancreatic cancer, high-risk pancreatic neuroendocrine tumors (PNETs) and pancreatic cystic neoplasms (PCNs). However, a majority of pancreatic cancers are unresectable at the time of diagnosis. In addition, surgical resection of pancreatic lesions can be associated with morbidity and mortality. A less-invasive alternative therapeutic intervention to avoid short term and long-term adverse events is desirable, as is a minimally-invasive palliative therapy for unresectable or recurrent pancreatic cancers. Endoscopic ultrasound guided radiofrequency ablation (EUS-RFA) allows for selective tissue ablation with minimal injury to the surrounding tissue. EUS-RFA of pancreatic tumors has shown high clinical and technical success with acceptable side effects in pancreatic lesions, lymph nodes, and the celiac plexus. This paper will review the pathophysiology, available technology, safety and efficacy, and future directions of EUS-RFA.
\end{abstract}

Keywords: Endoscopic ultrasound guided radiofrequency ablation (EUS-RFA); pancreatic cancer; pancreatic lesions; pancreatic cystic neoplasm and pancreatic neuroendocrine tumors

Received: 23 June 2020; Accepted: 18 August 2020; Published: 25 April 2022.

doi: $10.21037 /$ tgh-2020-11

View this article at: http://dx.doi.org/10.21037/tgh-2020-11

\section{Introduction}

Pancreatic cancer is the fourth leading cause of cancer mortality despite its relatively low incidence (3\%) (1). It is postulated that it will become the second leading cause of cancer mortality if adequate measures are not taken $(2,3)$. In addition, with advances of conventional imaging modalities, more asymptomatic pancreatic lesions are being incidentally discovered. Incidentally discovered lesions mostly include pancreatic cystic neoplasms (PCNs) and neuro endocrine tumors of the pancreas (PNETs). PCNs often have a benign trajectory, though some, like intraductal papillary mucinous neoplasms (IPMNs) and mucinous cystadenomas (MCAs), have malignant potential (4). Neuroendocrine tumors represent a group of wide-ranging biological variability tumors comprising less than three percent of all primary endocrine malignancies. Incidence of PNETs has increased four to six-fold as a result of increasing cross-sectional imaging (5-7). PNETs are classified based on their grade (Ki-67) index and based on function as functional (10-30\%) or non-functional (70-90\%) (8).

Surgery is the management of choice in resectable pancreatic cancers. However, about $80-85 \%$ of pancreatic cancers are diagnosed at an advanced stage and not amenable to resection. Additionally, even after successful surgical resection for lesions detected early, the median survival after surgery is only $17-23$ months (9). Surgery is also the management of choice for PNETs. Conservative management may be considered in asymptomatic, incidentally discovered non-functioning PNETs of less than 2 centimeters in size (10-14). For larger, symptomatic PNETs and/or those involving the main pancreatic duct, bile duct, vascular or lymph nodes, surgical resection is the gold standard. Surgery can be curative for PNETs requiring 
resection, but it is also associated with significant short and long term adverse events (15). A recent systematic review of the literature by Jilesen $e t$ al., included 62 studies evaluating the post-operative complications, in-hospital mortality and survival rate after surgical resection with PNETs $(16,17)$. It was noted that pancreatic fistula is the most common cause of morbidity and noted in about $45 \%$ of cases after tumor enucleation. This study also documented other complications like delayed gastric emptying (5-18\%), pancreatic pseudocyst, post-operative hemorrhage ( $1 \%$ to $7 \%$ ) and in-hospital mortality (3\% to 6\%).

For PNETs, a less-invasive alternative therapeutic intervention to avoid short term and long-term adverse events is desirable. In addition, there is a need for minimally-invasive palliative therapies for unresectable or recurrent pancreatic cancers. Endoscopic ultrasound guided radiofrequency ablation (EUS-RFA) allows for selective tissue ablation with minimal injury to the surrounding tissue. This is particularly important as pancreatic tumors often infiltrate, encase, or abut important structures that if damaged can lead to severe adverse effects. RFA has been successfully and more readily used in liver tumors compared to the pancreas due to the biological, anatomical and thermal differences. However, EUS-RFA of pancreatic lesions has shown high clinical and technical success with acceptable side effects (18). EUS-RFA has also shown efficacy in lymph nodes ablation and celiac plexus neurolysis. This paper will review the pathophysiology, available technology, safety and efficacy, and future directions of EUS-RFA.

\section{Pathophysiology of radiofrequency ablation}

RFA causes tissue injury by focal hyperthermia which is thought to alter tumor microenvironment, ultimately damaging cells at the membrane and subcellular levels (19). Temperatures between 60 to $100{ }^{\circ} \mathrm{C}$ are generated by a high-frequency alternating current and the ions in the tissue attempt to follow the changing directions of the alternating current (20). Post-RFA ablation, the lesion is noted to have three zones: a central zone of coagulative necrosis, a peripheral or transitional zone of sub-lethal hyperthermia, and surrounding unaffected tissue $(19,21,22)$. Temperatures greater than $100{ }^{\circ} \mathrm{C}$ is less effective, as the ablation at this temperature causes water vapor and burnt tissue, resulting in increasing tissue impedance and decreased efficacy. Of note, one limitation of RFA ablation is the heat-sink effect which makes tumor tissue adjacent to vasculature less susceptible to thermal damage. It is postulated that the heat is dissipated with the flowing blood thus decreasing the efficacy of RFA $(19,23)$.

In addition to direct injury, EUS-RFA is postulated to also induce an immune response. In the transitional zone, multiple studies have shown in increase in inflammatory infiltrates as well as B cell $\mathrm{s}$ and $\mathrm{T}$ cells that are specific to the ablated tissue (24-26). These immune cells were noted in distant untreated tumors and also in the blood stream. Various immunogenic intracellular substrates released post hyperthermic injury like RNA, DNA, heat shock protein 70 , high mobility group protein B1 and uric acid-trigger innate immunity to tumor tissue.

\section{Available technology}

Two main types of RFA electrodes for use via endoscopic ultrasound are available currently. Monopolar RFA has a closed-loop circuit which includes a Radiofrequency generator, an electrode needle, a ground pad and the patient. Habib ${ }^{\mathrm{TM}}$ EUS-RFA (1 Fr, EMcision Ltd., London, UK), 19 G EUS-RFA (Radionics, Inc., Burlington, MA, USA) and EUSRA RF electrode (18/19 G, STARmed, Koyang, Korea) are the monopolar electrodes that are used for the pancreas. Bipolar RFA has two interstitial electrodes delivering energy, which precludes the need for patient grounding $(20,27,28)$. Hybrid cryotherm probe (14 G, Hybrid-Therm; ERBE, Tubingen, Germany) is the bipolar electrode that is reported (27,29-32). In the United States, only the Habib EUS-RFA probe and the EUSRA RF electrode are approved by the FDA. The hybrid cryotherm probe is approved for use in Europe.

The Habib ${ }^{\mathrm{TM}}$ EUS-RFA probe is a fiber that is advanced through a fine-needle aspiration needle and into the target lesion. The EUSRA RF is a needle-type probe. The metal part of the needle is insulated over the entire length except the naked terminal tip (length of which varies from 5-26 mm). The RFA probes are connected to generators and are designed to deliver accurate energy to target lesion. The needle tip or probe tip is introduced and positioned at the far end of the target lesion. Energy is delivered after confirming placement by EUS (Figure 1). After a lag period, echogenic bubbles appear around the needle confirming the ablation of the tissue. In larger lesions, the electrode can be repositioned to ablate another zone along the same trajectory or by using a fanning technique (Video 1: EUSRFA). Additional passes can be made until the desired ablation effect is obtained $(27,33)$. It is recommended to 


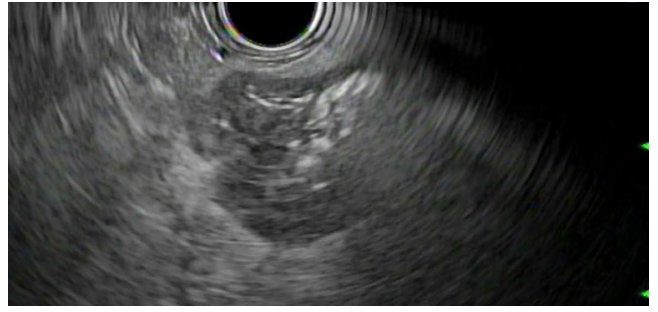

Figure 1 EUSRA needle delivering RFA energy in a pancreatic lesion. RFA, radiofrequency ablation.

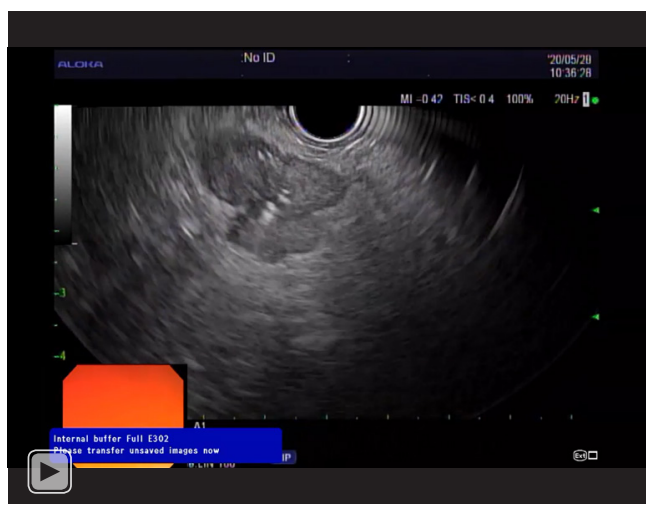

Video 1 EUSRA needle delivering RFA energy in a pancreatic lesion. RFA, radiofrequency ablation.

leave a "security ring" of at least $5 \mathrm{~mm}$ at the periphery of the tumor in order to avoid thermal injuries to nearby structures $(34,35)$. Crinò et al. reported that lower wattage, applied for a longer time can result in a greater but slower damage. In this study they used $30 \mathrm{~W}$ for an average time period of $50 \mathrm{~s}$, which reduced the number of applications to 1.5 on average. This is called "thermal diffusivity effect" which is based on thermal conductivity in neoplastic tissue. Heat spreads inside the neoplastic tissue but not outside making the procedure safer and easier to control $(34,36)$. Higher power settings were paradoxically noted to achieve smaller radial length or small ablation zones. This is because of rapid charring around the needle at high power with subsequent increased impedance which interferes with the conduction of the current and decreases the ablation diameter (37).

\section{Safety and efficacy}

\section{EUS-RFA in animal studies}

Goldberg et al. first reported the use of EUS-RFA of the normal pancreas in pigs in 1999. They documented good correlation between imaging and gross pathology for lesions $>5 \mathrm{~mm}$. Minimal complications of transmural gastric burns, serosal small intestinal burn, elevated lipase with focal pancreatitis were observed with no major complications noted (38). Carrara et al. studied the hybrid cryotherm probe in pigs, which uses bipolar RFA with cryotechnology. Complications included pancreatitis, gastric wall burn and adhesions between pancreas and gut with no documented mortality. Gaidhane et al. evaluated EUS-RFA of the pancreatic head using Habib EUS-RFA catheter in pigs, which was well tolerated with minimum amount of pancreatitis (39). The demonstrated safety of EUS-RFA in animal studies has encouraged the use of EUS-RFA in humans.

\section{EUS-RFA for PNETs and PCNS}

Rossi et al. reported the first prospective study on RFA for the treatment of PNETs who were non-eligible or unwilling to undergo surgery. RFA was successfully performed in ten patients using percutaneous $(n=6)$, intra-operative $(n=3)$ or under EUS guidance $(n=1)$. Major complications included acute pancreatitis in 3 patients who underwent RFA (percutaneous, $\mathrm{n}=1$; intraoperative, $\mathrm{n}=2$ ). Out of these two patients developed pancreatic fluid collections that were successfully managed with ultrasound-guided drainage and endoscopy. No complications were noted during the EUS approach (40).

Barthet et al. conducted a prospective multicenter study that included 12 patients who had 14 PNETs with mean size of $13.1 \mathrm{~mm}$ and 17 patients who had PCNs (16 IPMN s and 1 mucinous cystadenoma) with mean size of $28 \mathrm{~mm}$. Among 14 PNETS, at 1-year follow-up $12 \mathrm{had}$ completely disappeared (86\% tumor resolution). Among 17 PCNS, 71\% had significant response rate. Pancreatitis and one small bowel perforation were reported in the first two patients. However, after adjusting the protocol, in subsequent patients only one complication of pancreatic ductal stenosis occurred (4).

Pai et al. reported EUS-RFA of eight patients in a prospective multi-center trial. Six had PCNs and two had PNETs. The applied power varied from 5-25 Watts and the mean number of applications was 4.5 . They reported complete resolution of cysts in 2 patients $(48.4 \%)$ and size reduction in 3 patients (\%). Two patients had mild abdominal pain which resolved spontaneously. No other adverse events were reported (30). 
Oleinkov et al. reported a retrospective study which included 18 patients with PNETs: 7 insulinoma patients and 11 with non-functional PNETs. Twenty-seven lesions with mean diameter of $14.3 \pm 7.3 \mathrm{~mm}$ were treated. Technical success was determined by typical post ablative changes on surveillance imaging which was detected in 26 out of 27 lesions. Clinical response was noted in all insulinoma patients within 24 hours of treatment. No major complications were noted. No clinically significant recurrences were noted during a mean follow up of $8.7 \pm 4.6$ months $(41)$.

Lakhtakia et al. reported 3 patients with functional PNETs (Insulinoma) having symptomatic hypoglycemia who underwent EUS-RFA using 19 G EUSRA ${ }^{\mathrm{TM}}$ (STAR med) with rapid symptomatic and biochemical improvement within 2 days after RFA in all patients. Two-year followup of these patients demonstrated sustained response (29). Waung et al. $(18 \mathrm{~mm})$, Choi et al. $(12 \mathrm{~mm})$ and Bas-Cutrina et al. $(10 \mathrm{~mm})$, each reported one case of successful EUSRFA ablation of insulinoma $(33,42,43)$.

\section{EUS-RFA for pancreatic cancer}

Girelli et al. reported a prospective study of ultrasound guided RFA during laparotomy in fifty patients with locally advanced pancreatic cancer. Abdominal adverse events occurred in $24 \%$ of the patients, related to direct thermal injury (four cases of portal vein thrombosis and two pancreatic fistulas). They documented when they reduced the applied heat from 105 to 90 degrees $C$ there was significant reduction in adverse events (44). Cantore et al. reported that the overall survival was significantly higher in RFA following any other primary treatment compared to primary RFA alone in locally advanced pancreatic cancer (45).

Choi et al. reported a prospective study of EUS RFA in benign solid pancreatic tumors with a technical success rate of $100 \%$. Radiologic complete remission was achieved in $70 \%$ and median diameter changed from 20 to $6.5 \mathrm{~mm}$ (58.9\% reduction in the lesion). In addition, change in vascularity and central necrosis was demonstrated after EUS-RFA. Abdominal pain and pancreatitis were the adverse events reported. In the patient with pancreatitis, the lesion was located in close proximity to the main pancreatic duct (4 mm away) Prophylactic pancreatic duct stenting was performed in this patient prior to the second session of RFA to prevent post-procedure pancreatitis (33).

Crinò et al. reported a retrospective analysis of 9 patients with locally advanced pancreatic. The mean number of applications was 1.5 and mean time of RFA application was 58 secs. Three patients reported mild abdominal pain, managed conservatively with NSAIDs. No adverse events or mortality noted during the follow up (34).

Lastly, Song et al. used 18-guage RFA electrode to deliver 20 to $50 \mathrm{~W}$ power for 10 seconds in 6 patients. The mean diameter of pancreatic masses was $3.8 \mathrm{~cm}$. They demonstrated significant improvement in the size of the lesion after treatment with RFA with no adverse events or mortality (31).

\section{EUS-RFA combined studies}

Thosani et al. reported EUS-RFA efficacy in a multicenter retrospective study which included 21 patients. Pancreatic ductal adenocarcinoma was most common lesions (47.6\% of patients), followed by functioning PNETS (14.3\%). Median follow up was 5 months. They reported significant decrease in the size of the lesion, technical success of $100 \%$ and only one post procedure complication of worsening abdominal pain (46).

Alvarez-Sanchez et al. reported a review of 42 patients from several case series who underwent EUS-RFA for a variety of pancreatic lesions: unresectable pancreatic cancer in 28 patients, PNETs in 7, mucinous cysts in 4 and microcystic adenoma in 1 . Technical success was achieved in 36 patients $(86 \%)$. The selected power and application time varied between studies, from 5 to $50 \mathrm{~W}$ and from 10 to $360 \mathrm{~s}$ (47). There was no procedure-related mortality, mild early complications were observed in 9 of 36 patients (25\%), and only one case of mild acute pancreatitis occurred.

\section{EUS-hybrid cryotherm probe studies}

Arcidiacono et al. reported a prospective study of patients with locally advanced pancreatic adenocarcinoma after standard chemoradiotherapy failure. The procedure was feasible in $16 / 22$ patients; in 6 patients, the probe was unable to be passed inside the tumor due to GI wall stiffness, especially in patients who had already undergone radiation. No severe complications were reported during or immediately after the procedure. Early mild complications included abdominal pain with hyperamylasemia $(n=3)$ and mild duodenal bleeding $(\mathrm{n}=1)$, which was treated endoscopically. Late complications could be related to tumor progression. The study showed a direct correlation between application time and the treated area (48). 


\section{EUS-RFA other indications}

EUS RFA lymph node ablation has been performed in porcine models with no complications. It could be a potential area to explore for further use in patients with malignant or metastatic lymph nodes (49).

EUS-guided celiac ganglion RFA can be used for pain control in advanced pancreatic cancer. Jin et al. reported a case report with significant improvement in pain with reduction in narcotic intake with Habib ${ }^{\mathrm{TM}}$ RFA probe through 19 G EUS needle (50). However, the benefit of using EUS-RFA over the current standard EUS-guided celiac neurolysis using alcohol needs to be established by further studies.

\section{EUS-RFA and pancreatic duct stenting}

Prophylactic pancreatic duct stenting could be considered when the lesion is in close proximity to the main pancreatic duct. Barthet et al. reported one case of main pancreatic duct (MPD) stenosis after EUS-RFA of non-functioning PNET located in pancreatic neck, $1 \mathrm{~mm}$ from the MPD (4). Choi et al. reported one case of a pancreatic head lesion who developed pancreatitis post EUS-RFA. Pancreatic duct stenting was performed 7 days post-procedure and again prophylactically prior to the second session of RFA. Further data is needed to fully elucidate the role of pancreatic duct stenting during EUS-RFA (33).

\section{Adverse events}

Adverse events from EUS-RFA can range from mild abdominal pain with hyperamylasemia to acute pancreatitis, infection and perforation. In most studies, the adverse event rate improved with tailoring of the power settings suggesting that correct power settings is vitally important in minimizing the adverse event risk. In most studies, broad spectrum intravenous antibiotics were administered prior to the procedure to prevent post-procedure infection $(4,31,33,41)$. Barthet et al. used rectal diclofenac post EUS-RFA as recommended before endoscopic retrograde cholangiopancreatography (ERCP) to prevent post-ERCP pancreatitis (4). In all insulinoma cases, patients received a continuous $10 \%$ dextrose infusion before the procedure, along with close monitoring of glucose during and in the post-op period (41). Technical precautions such as maintenance of a $5-\mathrm{mm}$ safety margin from the MPD or peri-pancreatic vessels can also decrease the incidence of adverse events.

\section{Discussion}

EUS-RFA is an emerging technology for pancreatic lesions. Literature has shown high clinical and technical success rates with acceptable side effect profiles $(18,33,34)$.

Pancreatic RFA was initially performed during palliative surgery and showed encouraging results $(44,51)$. However severe adverse events like thermal-induced pancreatitis, duodenal or biliary injuries have been reported after intraoperative and percutaneous pancreatic RFA $(34,40)$. The absence of internal cooling mechanism of the RFA probes used for percutaneous or during intra-operative routes is possibly the potential cause of higher number of reported complications. With the internal cooling system of EUS -RFA probes, the same has not been observed.

EUS-RFA has been evaluated in humans for PNETs, PCNs, and pancreatic cancers. The bulk of literature lies with PNETs and PCNs in patients who are not surgical candidates and shows overall excellent efficacy and safety. The use of EUS-RFA in pancreatic cancer is starting to be studied with preliminary data showing encouraging results. However, the pancreas is very thermal sensitive organ in close proximity to other important vasculature and organs. This poses difficulty in standardizing pancreatic RFA protocols. Direct cellular injury is dependent on tissue impedance, procedure time, duration, power wattage, number of RFA applications per session and number of sessions. These were variable in different studies and evidence is scarce as most studies were done in retrospectively in small and heterogenous group of patients. In addition, clinical efficacy is not fully elucidated due to lack of long-term follow up in the majority of studies. Though cyto-reduction can be documented, improvement in quality of life, improved survival or symptom free intervals for functional NETs remains unknown. Prospective studies are now underway and will hopefully overcome these early limitations.

The potential applications for EUS-RFA are vast. EUSRFA can be potentially used as a palliative therapy for unresectable pancreatic cancer to reduce tumor burden and improve the efficacy of chemotherapy by increasing vascularity of the post-ablated lesion. Pending further evaluation, it could even be used as neoadjuvant therapy to downgrade borderline resectable or locally advanced tumors prior to surgical resection. For PNETs, EUS-RFA may become an alternative or even replacement for surgical resection.

In conclusion, EUS-RFA is an emerging modality with 
high technical success and acceptable side affect profile. Current small heterogenous studies pose difficulty to standardize the pancreatic RFA protocol and leave longterm potential benefits in quality of life and overall survival unknown. Prospective randomized controlled trials are needed and underway to confirm efficacy and evaluate longterm benefits.

\section{Acknowledgments}

Funding: None.

\section{Footnote}

Provenance and Peer Review: This article was commissioned by the editorial office, Translational Gastroenterology and Hepatology for the series "Innovation in Endoscopy". The article has undergone external peer review.

Conflicts of Interest: Both authors have completed the ICMJE uniform disclosure form (available at https://tgh. amegroups.com/article/view/10.21037/tgh-2020-11/coif). The series "Innovation in Endoscopy" was commissioned by the editorial office without any funding or sponsorship. AT served as the unpaid Guest Editor of the series and serves as an unpaid editorial board member of Translational Gastroenterology and Hepatology from April 2019 to March 2023. AT has done consulting for EndoGastric Solutions, Boston Scientific, and Steris Endoscopy, outside the submitted work. The authors have no other conflicts of interest to declare.

Ethical Statement: The authors are accountable for all aspects of the work in ensuring that questions related to the accuracy or integrity of any part of the work are appropriately investigated and resolved.

Open Access Statement: This is an Open Access article distributed in accordance with the Creative Commons Attribution-NonCommercial-NoDerivs 4.0 International License (CC BY-NC-ND 4.0), which permits the noncommercial replication and distribution of the article with the strict proviso that no changes or edits are made and the original work is properly cited (including links to both the formal publication through the relevant DOI and the license). See: https://creativecommons.org/ licenses/by-nc-nd/4.0/.

\section{References}

1. Siegel RL, Miller KD, Jemal A. Cancer statistics, 2019. CA Cancer J Clin 2019;69:7-34.

2. Aier I, Semwal R, Sharma A, et al. A systematic assessment of statistics, risk factors, and underlying features involved in pancreatic cancer. Cancer Epidemiol 2019;58:104-10.

3. Rahib L, Smith BD, Aizenberg R, et al. Projecting cancer incidence and deaths to 2030: the unexpected burden of thyroid, liver, and pancreas cancers in the United States. Cancer Res 2014;74:2913-21.

4. Barthet M. Endoscopic ultrasound-guided radiofrequency ablation for pancreatic neuroendocrine tumor. Ann Endocrinol (Paris) 2019;80:182-4.

5. Kuo EJ, Salem RR. Population-level analysis of pancreatic neuroendocrine tumors $2 \mathrm{~cm}$ or less in size. Ann Surg Oncol 2013;20:2815-21.

6. Dasari A, Shen C, Halperin D, et al. Trends in the Incidence, Prevalence, and Survival Outcomes in Patients With Neuroendocrine Tumors in the United States. JAMA Oncol 2017;3:1335-42.

7. Hallet J, Law CH, Cukier M, et al. Exploring the rising incidence of neuroendocrine tumors: a population-based analysis of epidemiology, metastatic presentation, and outcomes. Cancer 2015;121:589-97.

8. Partelli S, Bartsch DK, Capdevila J, et al. ENETS Consensus Guidelines for Standard of Care in Neuroendocrine Tumours: Surgery for Small Intestinal and Pancreatic Neuroendocrine Tumours. Neuroendocrinology 2017;105:255-65.

9. Vincent A, Herman J, Schulick R, et al. Pancreatic cancer. Lancet 2011;378:607-20.

10. Lee LC, Grant CS, Salomao DR, et al. Small, nonfunctioning, asymptomatic pancreatic neuroendocrine tumors (PNETs): role for nonoperative management. Surgery 2012;152:965-74.

11. Gaujoux S, Partelli S, Maire F, et al. Observational study of natural history of small sporadic nonfunctioning pancreatic neuroendocrine tumors. J Clin Endocrinol Metab 2013;98:4784-9.

12. Kishi $Y$, Shimada K, Nara S, et al. Basing treatment strategy for non-functional pancreatic neuroendocrine tumors on tumor size. Ann Surg Oncol 2014;21:2882-8.

13. Rosenberg AM, Friedmann P, Del Rivero J, et al. Resection versus expectant management of small incidentally discovered nonfunctional pancreatic neuroendocrine tumors. Surgery 2016;159:302-9.

14. Sadot E, Reidy-Lagunes DL, Tang LH, et al. Observation 
versus Resection for Small Asymptomatic Pancreatic Neuroendocrine Tumors: A Matched Case-Control Study. Ann Surg Oncol 2016;23:1361-70.

15. Larghi A, Rizzatti G, Rimbaş $M$, et al. EUS-guided radiofrequency ablation as an alternative to surgery for pancreatic neuroendocrine neoplasms: Who should we treat? Endosc Ultrasound 2019;8:220-6.

16. Jilesen AP, van Eijck CH, in't Hof KH, et al. Postoperative Complications, In-Hospital Mortality and 5-Year Survival After Surgical Resection for Patients with a Pancreatic Neuroendocrine Tumor: A Systematic Review. World J Surg 2016;40:729-48.

17. Jilesen AP, van Eijck CH, Busch OR, et al. Postoperative Outcomes of Enucleation and Standard Resections in Patients with a Pancreatic Neuroendocrine Tumor. World J Surg 2016;40:715-28.

18. Dhaliwal A, Dhindsa B, Choa J, et al. Efficacy of Endoscopic Ultrasound Radiofrequency Ablation in the Treatment of Pancreatic Tumors: Is It Ready for Prime Time? A Systematic Review and Meta-Analysis: 7. Am J Gastroenterol 2019;114:S4.

19. Chu KF, Dupuy DE. Thermal ablation of tumours: biological mechanisms and advances in therapy. Nat Rev Cancer 2014;14:199-208.

20. McGahan JP, Brock JM, Tesluk H, et al. Hepatic ablation with use of radio-frequency electrocautery in the animal model. J Vasc Interv Radiol 1992;3:291-7.

21. Ahmed M, Brace CL, Lee FT Jr, et al. Principles of and advances in percutaneous ablation. Radiology 2011;258:351-69.

22. Nikfarjam M, Muralidharan V, Christophi C. Mechanisms of focal heat destruction of liver tumors. J Surg Res 2005;127:208-23.

23. Muralidharan V, Malcontenti-Wilson C, Christophi C. Effect of blood flow occlusion on laser hyperthermia for liver metastases. J Surg Res 2002;103:165-74.

24. Dromi SA, Walsh MP, Herby S, et al. Radiofrequency ablation induces antigen-presenting cell infiltration and amplification of weak tumor-induced immunity. Radiology 2009;251:58-66.

25. Wissniowski TT, Hansler J, Neureiter D, et al. Activation of tumor-specific $\mathrm{T}$ lymphocytes by radio-frequency ablation of the VX2 hepatoma in rabbits. Cancer Res 2003;63:6496-500.

26. Zerbini A, Pilli M, Laccabue D, et al. Radiofrequency thermal ablation for hepatocellular carcinoma stimulates autologous NK-cell response. Gastroenterology 2010;138:1931-42.
27. Lakhtakia S, Seo DW. Endoscopic ultrasonographyguided tumor ablation. Dig Endosc 2017;29:486-94.

28. McGahan JP, Gu WZ, Brock JM, et al. Hepatic ablation using bipolar radiofrequency electrocautery. Acad Radiol 1996;3:418-22.

29. Lakhtakia S, Ramchandani M, Galasso D, et al. EUSguided radiofrequency ablation for management of pancreatic insulinoma by using a novel needle electrode (with videos). Gastrointest Endosc 2016;83:234-9.

30. Pai M, Habib N, Senturk H, et al. Endoscopic ultrasound guided radiofrequency ablation, for pancreatic cystic neoplasms and neuroendocrine tumors. World J Gastrointest Surg 2015;7:52-9.

31. Song TJ, Seo DW, Lakhtakia S, et al. Initial experience of EUS-guided radiofrequency ablation of unresectable pancreatic cancer. Gastrointest Endosc 2016;83:440-3.

32. Armellini E, Crino SF, Ballare M, et al. Endoscopic ultrasound-guided radiofrequency ablation of a pancreatic neuroendocrine tumor. Endoscopy 2015;47 Suppl 1 UCTN:E600-1.

33. Choi JH, Seo DW, Song TJ, et al. Endoscopic ultrasoundguided radiofrequency ablation for management of benign solid pancreatic tumors. Endoscopy 2018;50:1099-104.

34. Crinò SF, D'Onofrio M, Bernardoni L, et al. EUS-guided Radiofrequency Ablation (EUS-RFA) of Solid Pancreatic Neoplasm Using an 18-gauge Needle Electrode: Feasibility, Safety, and Technical Success. J Gastrointestin Liver Dis 2018;27:67-72.

35. Paiella S, Salvia R, Ramera M, et al. Local Ablative Strategies for Ductal Pancreatic Cancer (Radiofrequency Ablation, Irreversible Electroporation): A Review. Gastroenterol Res Pract 2016;2016:4508376.

36. D'Onofrio M, Ciaravino V, De Robertis R, et al. Percutaneous ablation of pancreatic cancer. World J Gastroenterol 2016;22:9661-73.

37. Rustagi T, Chhoda A. Endoscopic Radiofrequency Ablation of the Pancreas. Dig Dis Sci 2017;62:843-50.

38. Goldberg SN, Mallery S, Gazelle GS, et al. EUS-guided radiofrequency ablation in the pancreas: results in a porcine model. Gastrointest Endosc 1999;50:392-401.

39. Gaidhane M, Smith I, Ellen K, et al. Endoscopic Ultrasound-Guided Radiofrequency Ablation (EUS-RFA) of the Pancreas in a Porcine Model. Gastroenterol Res Pract 2012;2012:431451.

40. Rossi S, Viera FT, Ghittoni G, et al. Radiofrequency ablation of pancreatic neuroendocrine tumors: a pilot study of feasibility, efficacy, and safety. Pancreas 2014;43:938-45.

41. Oleinikov K, Dancour A, Epshtein J, et al. Endoscopic 
Ultrasound-Guided Radiofrequency Ablation: A New Therapeutic Approach for Pancreatic Neuroendocrine Tumors. J Clin Endocrinol Metab 2019;104:2637-47.

42. Waung JA, Todd JF, Keane MG, et al. Successful management of a sporadic pancreatic insulinoma by endoscopic ultrasound-guided radiofrequency ablation. Endoscopy 2016;48 Suppl 1:E144-5.

43. Bas-Cutrina F, Bargallo D, Gornals JB. Small pancreatic insulinoma: Successful endoscopic ultrasound-guided radiofrequency ablation in a single session using a 22-G fine needle. Dig Endosc 2017;29:636-8.

44. Girelli R, Frigerio I, Salvia R, et al. Feasibility and safety of radiofrequency ablation for locally advanced pancreatic cancer. Br J Surg 2010;97:220-5.

45. Cantore M, Girelli R, Mambrini A, et al. Combined modality treatment for patients with locally advanced pancreatic adenocarcinoma. Br J Surg 2012;99:1083-8.

46. Thosani N, Sharma NR, Raijman I, et al. 483 Safety and efficacy of endoscopic ultrasound guided radiofrequency ablation (EUS-RFA) in the treatment of pancreatic lesions: a multi-center experience. Gastrointest Endosc

doi: $10.21037 /$ tgh-2020-11

Cite this article as: Gollapudi LA, Tyberg A. EUS-RFA of the pancreas: where are we and future directions. Transl Gastroenterol Hepatol 2022;7:18.
2018;87:AB84.

47. Alvarez-Sanchez MV, Napoleon B. Review of endoscopic radiofrequency in biliopancreatic tumours with emphasis on clinical benefits, controversies and safety. World J Gastroenterol 2016;22:8257-70.

48. Arcidiacono PG, Carrara S, Reni M, et al. Feasibility and safety of EUS-guided cryothermal ablation in patients with locally advanced pancreatic cancer. Gastrointest Endosc 2012;76:1142-51.

49. Sethi A, Ellrichmann M, Dhar S, et al. Endoscopic ultrasound-guided lymph node ablation with a novel radiofrequency ablation probe: feasibility study in an acute porcine model. Endoscopy 2014;46:411-5.

50. Jin ZD, Wang L, Li Z. Endoscopic ultrasound-guided celiac ganglion radiofrequency ablation for pain control in pancreatic carcinoma. Dig Endosc 2015;27:163-4.

51. Spiliotis JD, Datsis AC, Michalopoulos NV, et al. Radiofrequency ablation combined with palliative surgery may prolong survival of patients with advanced cancer of the pancreas. Langenbecks Arch Surg 2007;392:55-60. 